Military Technical College

Kobry El-Kobbah, Cairo, Egypt

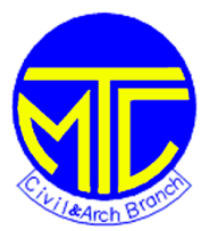

$10^{\text {th }}$ International Conference on Civil and Architecture Engineering

ICCAE-10-2014

\title{
CAMOUFLAGING AND CONCEALING STRUCTURES FROM VISUAL RECONNAISSANCE TECHNIQUES
}

\author{
Ahmed F. Gimiee ${ }^{1}$, Assoc. Prof. /Mohamed A. Barakat ${ }^{2}$, Assoc. Prof. /Ehab H. Mahmoud \\ ABSTRACT. \\ Camouflage and concealment are essential parts in the modern military \\ tactics specially after the increasing in the target recognition and acquisition \\ accuracy by means of reconnaissance and sensors systems.
}

The ability of gathering accurate overhead imagery for targets has increased dramatically over the last decades. Gathering information concerning important installations, by means of photo interpretation obtained from various reconnaissance systems such as spy satellites and Unmanned Ariel Vehicles (UAV'S) are the most effective threat opposing these installations.

Strategic and military installations such as headquarters, commanding posts, aircraft fortifications, air defence bases,...etc are the most important targets for the invading forces in any warfare to limit the military forces capabilities of any country.

This paper spotlights the building visual reconnaissance and surveillance detection methods, particularly military buildings, also the opposing camouflage and concealment techniques that shield them, the matter that will assist designers in creating guidelines for camouflage effectiveness in the visible spectrum. 


\section{Key Words.}

Architecture - Camouflage - Concealment - Important Buildings -Visual Reconnaissance.

1 MSc. Researcher, MTC, Cairo, Egypt.

2 Head of Architecture \& Civil engineering branch MTC, Cairo, Egypt.

3 Head of Architecture engineering department, MTC, Cairo, Egypt.

\section{1-INTROUDUCTION}

During the previous eras the art of warfare usually took the form of actions and reactions. The action was the continuous development of weapons, while the reaction was the progress in the fortification designs.

Nowadays new measures are added to the previous actions and reactions which are the reconnaissance and surveillance techniques as actions, while the art of camouflage, concealment and deception is the reaction.

Camouflage and concealment techniques were practiced by man from the early ages to hunt, preserves himself and in his warfare to deceive his opponent about his real intents. Starting from WWII huge developments of visual reconnaissance techniques took place and developed by time to be through UAV'S and spy satellites. This action leads to the need of innovating new reaction techniques for camouflage and concealment.

The three basic methods to camouflage and conceal installations are the twodimensional patterning, the three-dimensional patterning, and the screening. They can be used either single or combined and can be applied either to existing buildings or to new constructions.

This paper introduces camouflage and concealment methods that assists in making military assets appear to be part of the natural environment; it provides design guidelines for camouflage effectiveness in the visible spectrum.

\section{2- Reconnaissance and surveillance actions}

Reconnaissance is the act of obtaining information about the target area prior or after an attack and is accomplished by aerial photography or satellite imagery. 
Surveillance implies monitoring the target area for long periods and recording pertinent information such as construction layout, entrances and exits, activities and facility functions, accomplished by aerial photography, satellite imagery and intelligence gathering.

\subsection{Various reconnaissance and surveillance systems}

Sensors provide imagery during features identification, target recognition and target acquisition, the most predominant sensors wavebands are the radar, long wave infrared (LWIR), middle wave infrared (MWIR), near infrared (NIR), and visual wavebands, sensors can be classified into active or passive systems:[1, 2]

a. Active systems: These systems rely on using specific devices to propagate wave signals that hits any target and then reflected to be captured with a receiving devices such as radars and laser beam devices.

b. Passive systems: These systems rely on producing imagery without beam propagation. They collect energy that indicates the presence of a target, such as human eye, night-vision devices (NVDs), infrared (IR) imaging devices, acoustic sensors and photographic devices. They cannot be easily detected as there is no propagated beam.

\subsection{Visual sensors}

This research concerns with one of the passive systems (visual detection methods) which are the visual image produced from photographic devices due to visual sensors.

Visual sensors work in the parts of the electromagnetic (EM) spectrum between wavebands $400-700 \mathrm{~nm}$ that are visible to the human eye which can be aided by binoculars, telescopic sights and image intensifiers. 


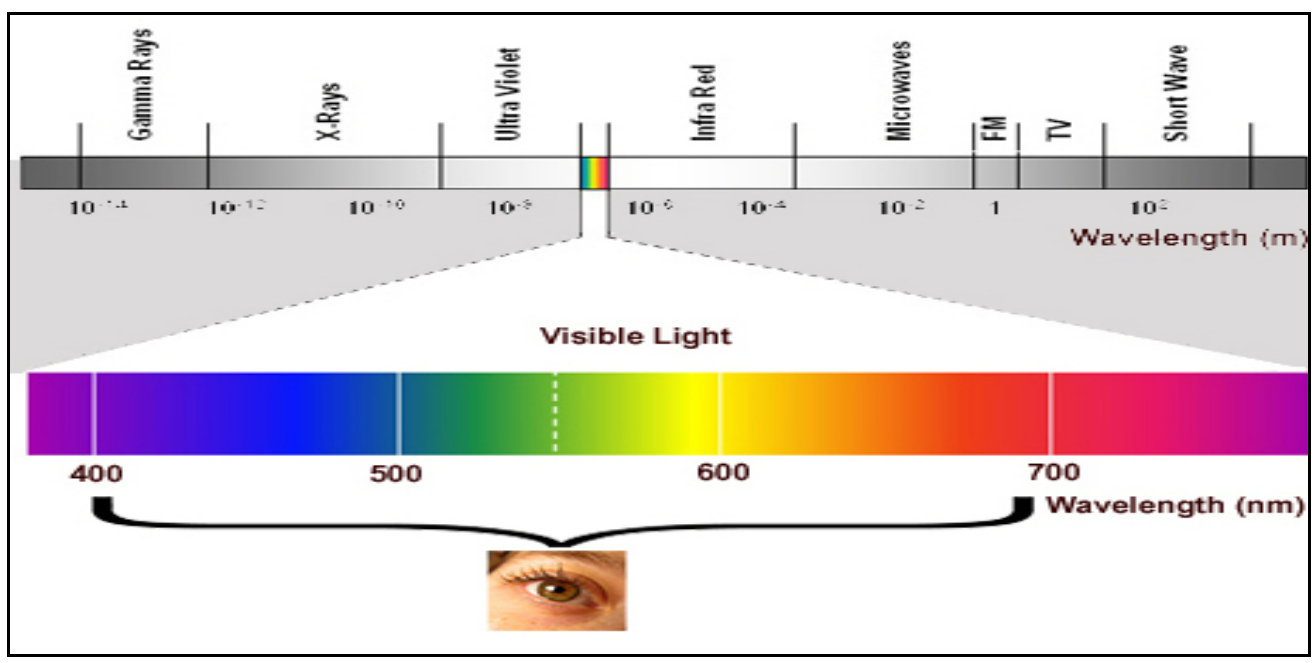

The electromagnetic spectrum [3]

Visual sensors are classified into three types [2]:

- Image intensifiers: Image intensifiers are passive night-observation devices. They amplify the low-level light that is present in even the darkest nights. These devices are used for surveillance and as weapon sights on small arms and vehicles. Airborne platforms are also capable of supporting image intensifiers.

- Low-light television (LLTV): LLTV combines image intensification with television technology; it is usually mounted on airborne platforms.

- Aerial recon, remote sensing and imagery: Aerial photography, satellite imagery and video imagery that allow image interpreters to record and study visual information produced by these sensors (visual cameras).

\subsection{Factors affecting visual recognition}

Regardless of the method of observation employed for visual detection, there are some factors which must always be present to aid the eye and the brain to identify an object. These factors are [4]:

A. Position: an object is often defined by its position with relative to its surroundings.

B. Shape: an object can be recognized by its shape or outlines. Every object has its distinctive features that assist in identifying it.

C. Shadow: Shadow, when viewed from air, is sometimes more revealing than the object itself. It aids photo interpreters in determining the height of 
objects. Sometimes it is important to break up or disrupt the shadow of an object than to conceal the object itself.

D. Texture: texture refers to the ability of an object to reflect, absorb and diffuse light. It is also the relative smoothness or roughness of a surface.

E. Color: color is an aid to the observer, especially when there is a contrast in color of an object with its background. The greater the contrast in color the more visible the object appears.

\section{3- Camouflage and concealment reactions}

Camouflage and concealment is properly the perfect reaction taken opposing visual reconnaissance and surveillance techniques. Some definitions have to be born in mind while dealing with this branch of science:

A. Camouflage: it is the process of using natural or artificial material on personnel, objects or installations with the aim of confusing, misleading or evading the enemy $[5,6]$

B. Concealment: It is process of protection from observation and surveillance. If concealment is the hiding of important installations or operations equipments then it is really one of the means of achieving camouflage.[5, 6]

C. Deception: Those measures designed to mislead the enemy by manipulation, distortion or falsification of evidence to induce him to react in a manner prejudicial to his interests. Deception is either active or passive.[5, 6]

a) Active deception: It is a planned series of lies with evidence to prove them to the hostilities.

b) Passive deception: Relies on secrecy and camouflage to hide capabilities and intentions from hostilities.

D. Camouflage, concealment \& deception (CCD): it is the use of materials and techniques to hide, blend, disguise, decoy or disrupt the appearance of important installations and equipments in their backgrounds. Designed CCD plan takes the advantage of the immediate environment and natural and artificial materials. [6] 
Effective CCD plan will cause the adversary to waste his resources, to spread and reduce his forces strength and tie up considerable forces at the wrong place in the wrong time. It will divert his attention from critical to insignificant areas, increase his confusion and reduce his certainty.

\section{4- Methods of visual camouflage and concealment}

Visual sensors are the most reliable sensors that represent threats to important installations [7]. Thus, CCD techniques effective in visual portion of the EM spectrum are extremely important to be applied.

For camouflaging and concealing installations, three techniques can be applied either individually or combined with each others. These techniques are:
a. The two-dimensional pattering.
b. The three-dimensional pattering.
c. The screening.

\subsection{Two-Dimensional Patterning}

This method has been successfully used in camouflaging constructions requiring flat or nearly flat patterns. Two-dimensional patterning is applied to flat surfaces like roofs, walls or the ground. Two-dimensional patterning can be achieved by:

a. Painting and texturing patterns: Disruptive or pattern painting are used to 'break up' and change the characteristic appearance of a flat surface. The shape and the shadow of an existing building can be disrupted by pattern painting on walls, roof or the ground around it. To accomplish this, irregular patterns of colors that simulate the local pattern are applied in such a way that the straight edges are broken up.

From other side different types of texturing can be used to reduce the shining of smooth surfaces and to produce variations of tones to decrease identification against background. 

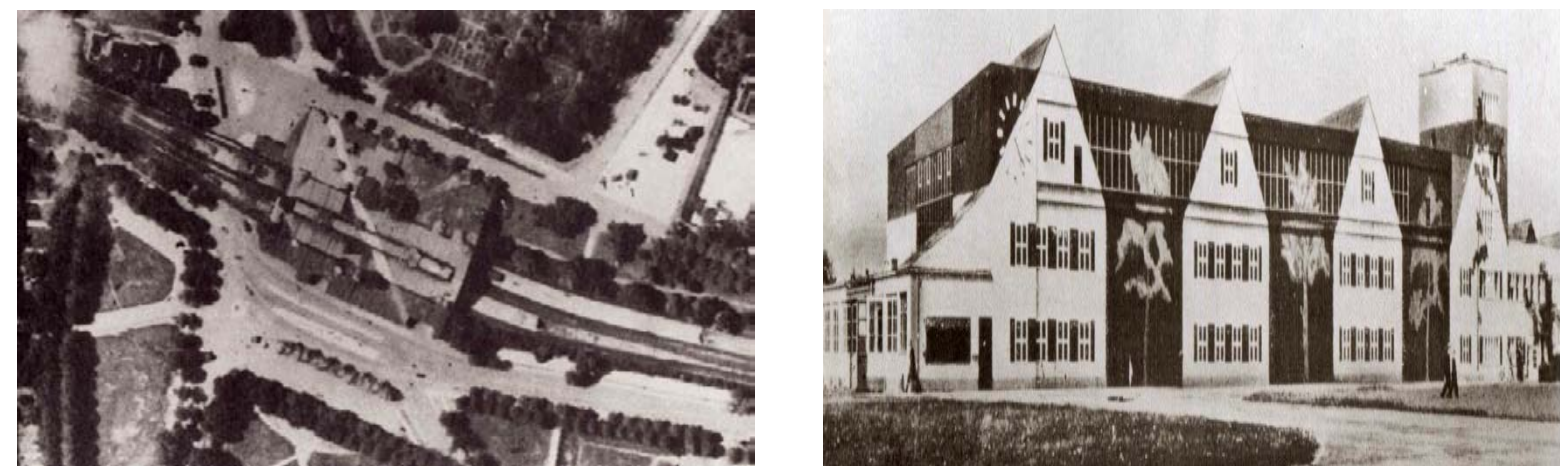

Left: Hamburg Railway station camouflaged to be as a part of the adjacent urban pattern Right: British aircraft hangers painted to look like houses and trees [8]
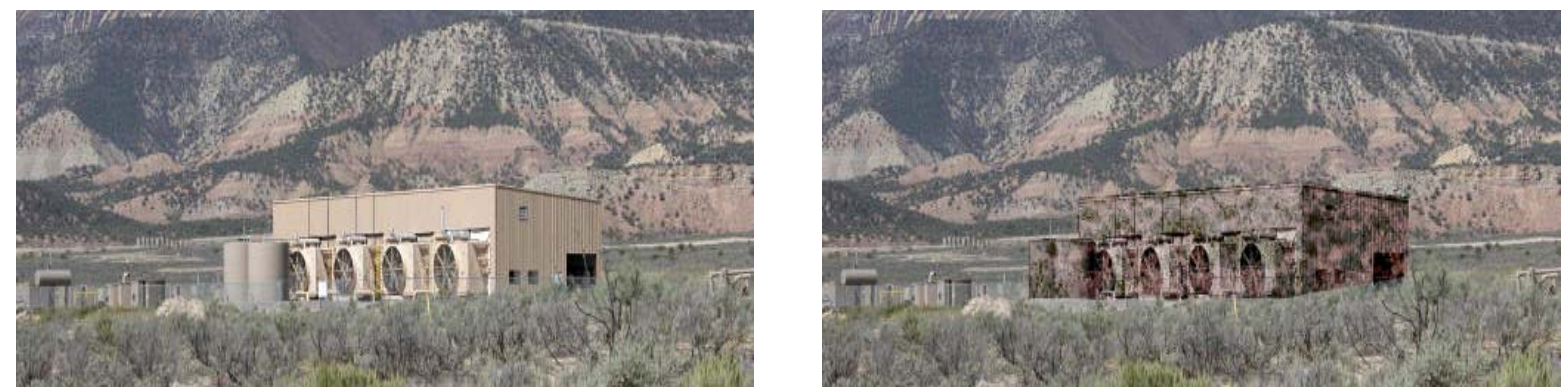

Military installation before and after applying disruptive painting [9]

b. Controlling agriculture: By controlling irrigation, fertilization and grass seeding to provide a comparatively quick and natural colored cover for the earth around new constructions.

c. Controlling Mowing: By Cutting areas of grass, hay or similar growth to different heights to give varies textures to a field. Varying directions of cutting produces marked changes in both texture and color.
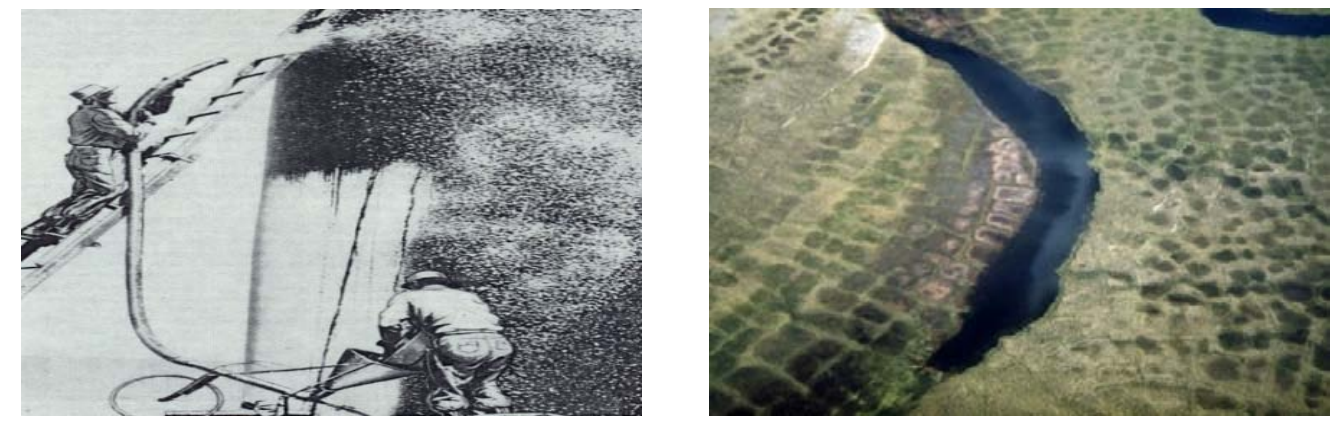

Left: Texturing materials being applied in an improvised pattern [10]

Right: Aerial view of patterned ground [11]

Since the controlling factor in aerial reconnaissance is the appearance from air, so the lower the level of aerial observation, the less the effectiveness of the twodimensional patterning. This fact leads to the use of the three-dimensional pattering. 


\subsection{Three-Dimensional Patterning}

Three-dimensional patterning is applied to all types of structures. It is more realistic because it casts shadows and is more preferable than two-dimensional patterning. It is satisfactory for a large portion of most camouflage projects.

Three-dimensional patterning can be applied by[10] :

a. False structures: used to make existing installations or fortifications look like different types of structures by using prefabricated forms made from materials such as wood, plaster, cloth, garnished netting or using any native materials.
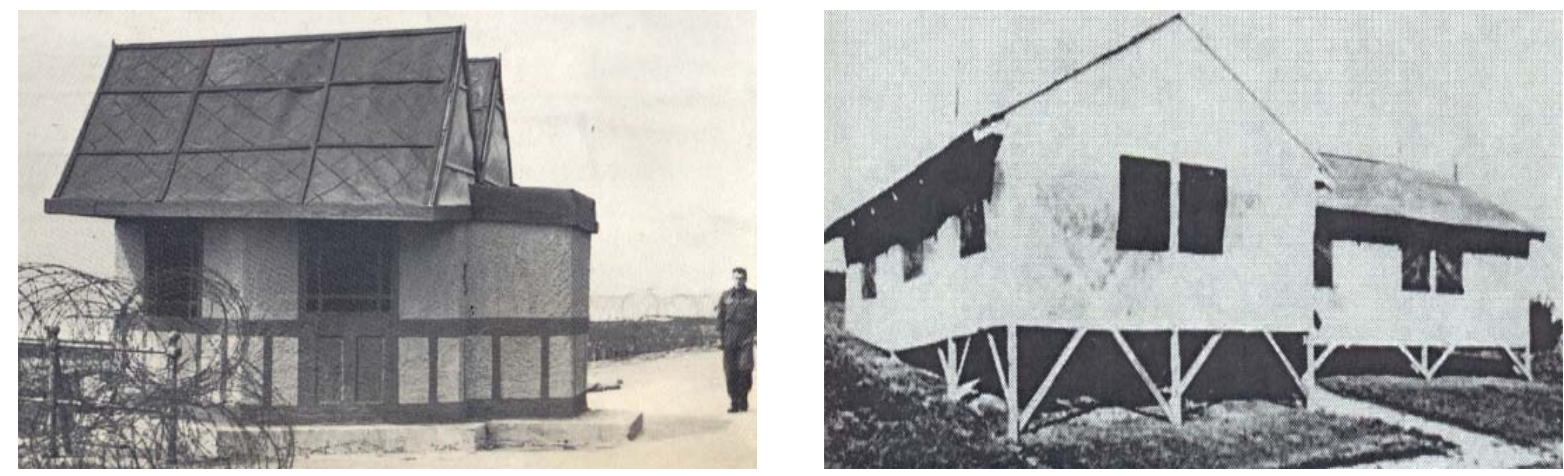

Left: Camouflaged British coastal defenses using false structures [12]

Right: A Full-scale decoy house [10]
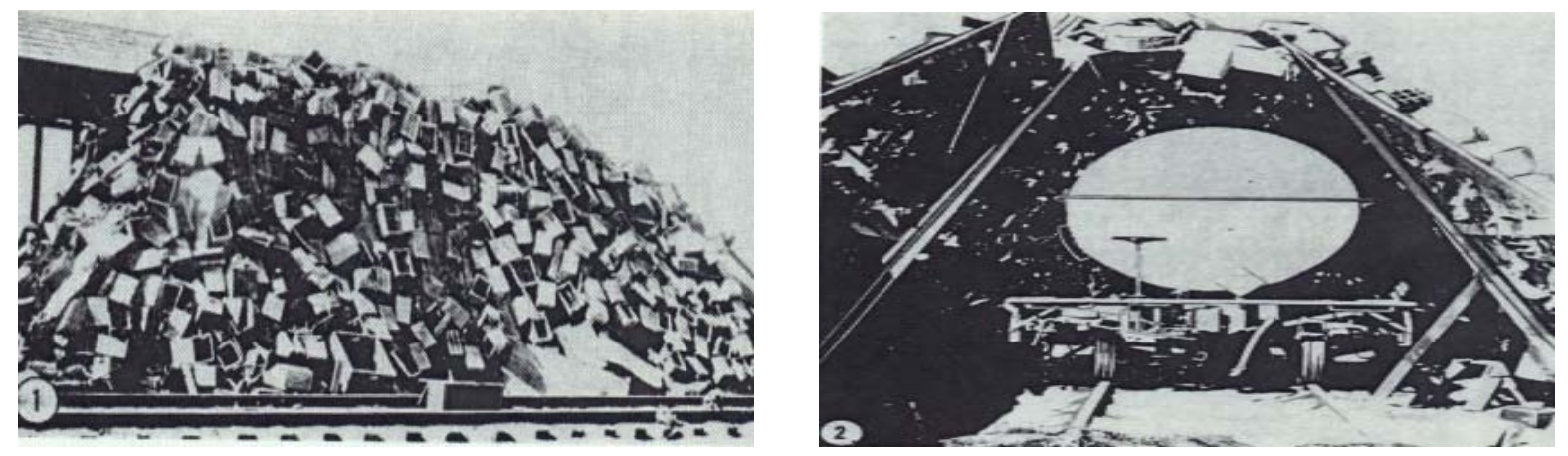

Left: Wood and paper boxes wired to framework to conceal a supply tank Right: Inside view of the concealed area [10]

b. Real and False plants: Trees and shrubs can be transplanted in clumps to create dark masses or on the shadow sides of installations to break up the regular shadows. 

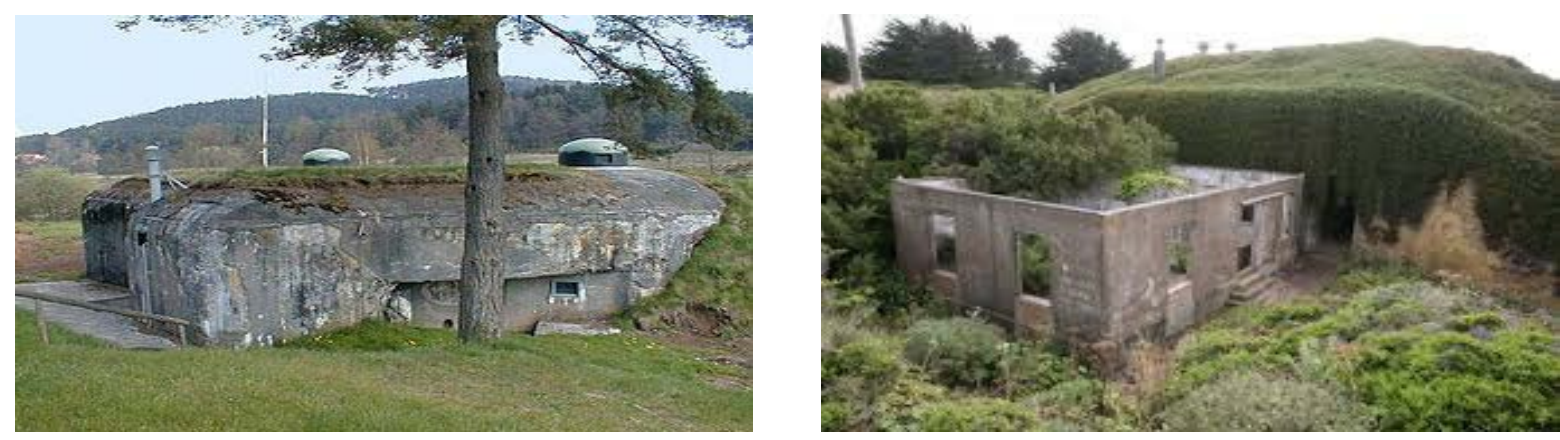

Left: Cultivated Roof of Maginot line [13]

Right: Fort Barry cultivated roof [14]

c. False Terrain Features: Materials may be arranged on the ground to imitate terrain features. Like crumpled paper, sagebrush, tumbleweed or other bush materials that may be wired together and arranged to simulate terrain features.

d. Use natural contour: Accommodating installations in a simple regular slope and avoid locating it in a sharp slope contours assist in disguising one or more of its sides and manipulate the other sides with different camouflage method to merge it with the surroundings.

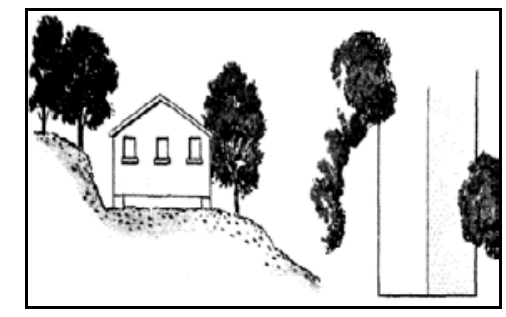

Without camouflage

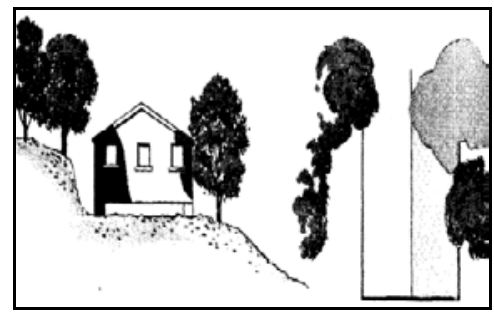

patterning with paint

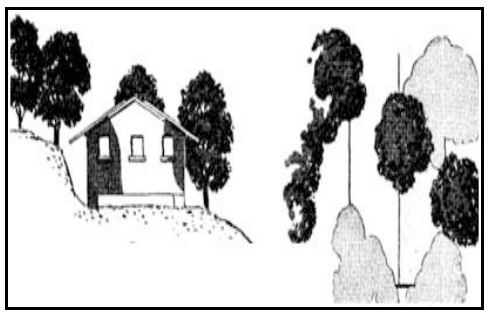

patterning with paint and artificial shrubberies

\subsection{Screening}

Screening can be used to eliminate the appearance of visual detection. This could be achieved by either garnished nets or smoke screens.

a. Garnished nets: This method depends on using a mesh of wire or fibre garnished with fabrics or synthetic materials as PVC (Polyvinyl Chloride) to conceal valuable assets beneath it. For long spans; garnished netting can be supported by wood or steel-truss or suspension-cable system. For shorter spans, simple posts or wire construction are adequate. 

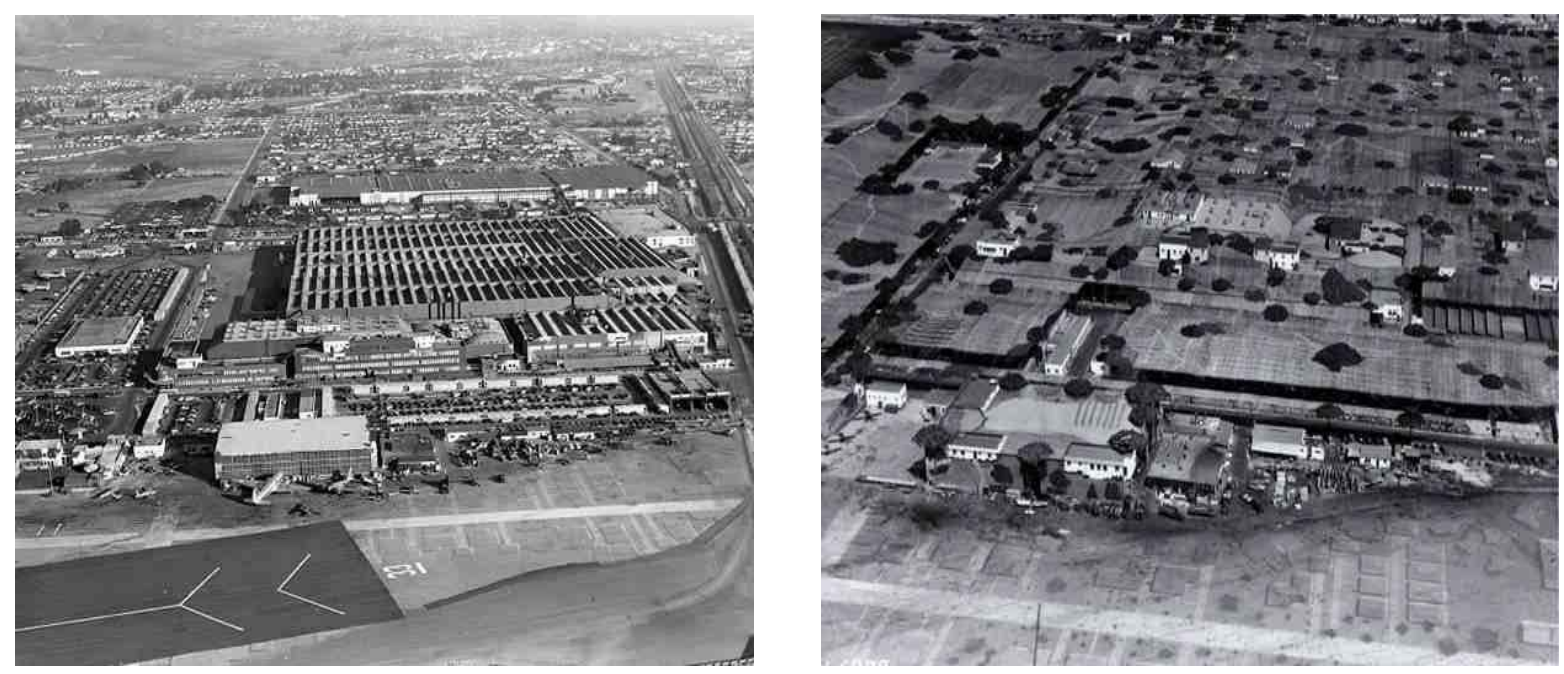

Camouflage nets supplied with false trees used During WWII in Lockheed Burbank aircraft plant in USA [15]
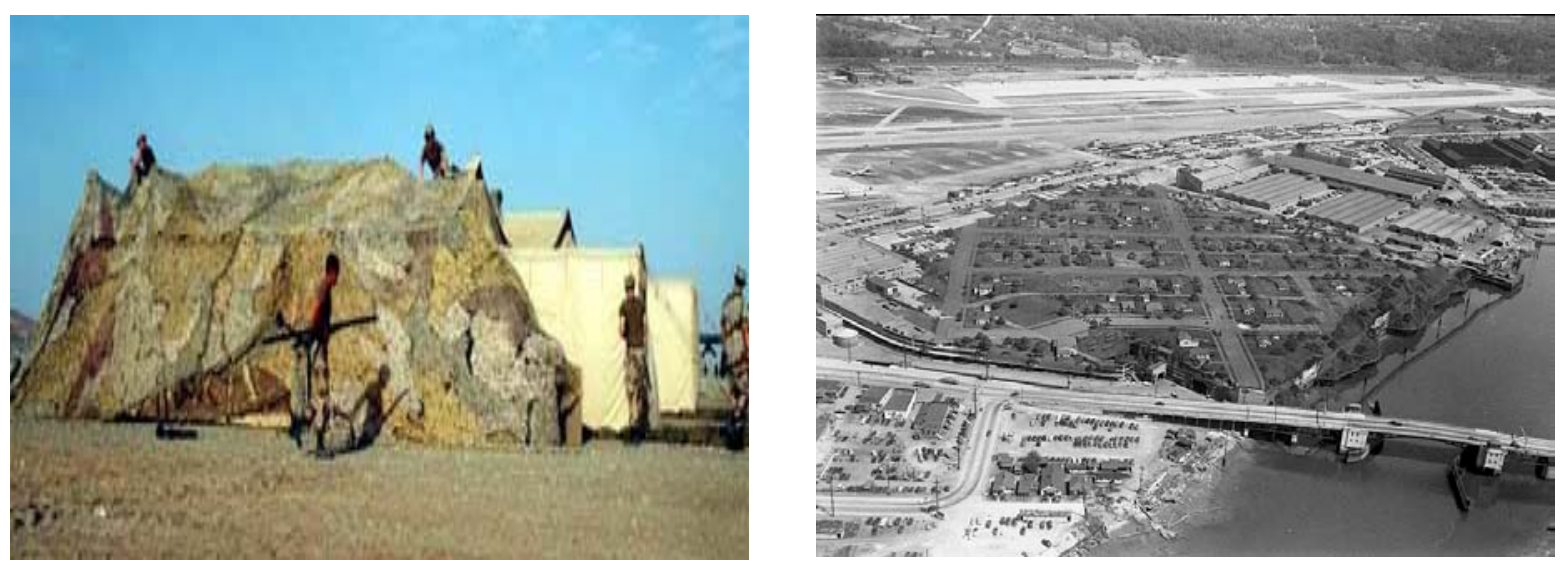

Left: Concealing individual or grouped buildings with nets [16]

Right: Boeing plant hidden by netting during WWII [17]

b. Smoke screens: This method depends on using special devices such as smoke generators or canister (such as a grenade) to produce smoke screens. Smoke has been used successfully to conceal important installations such as docks, bridges, and harbors from hostile aerial reconnaissance and attacks. For good coverage, the wind should be between (0.9 and 6.1) meter per second and the terrain should be fairly flat [10]. To prevent photographic observation, a smoke screen must be highly concentrated. Nowadays smoke screens have many colors that depend on the type of the chemical material producing it, the environment where it will be used and the purpose of using it. 

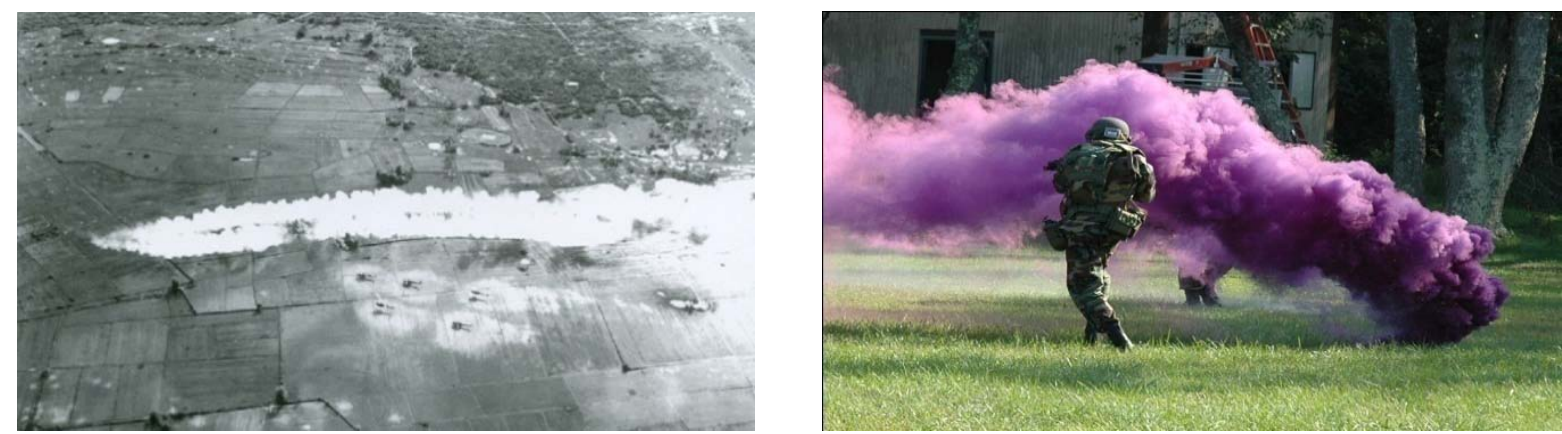

Left: Smoke-screens over land covering installation beneath it [18]

Right: A smoke grenade during a military training exercise[19]

\section{6- Design guidelines for camouflage effectiveness}

For achieving effective design methodology for concealing and camouflaging important installations against visual detection means, a procedure of design guidelines should be followed. This procedure has three main levels:

a) Site selection level.

b) Architecture design level.

c) Construction materials level.

\subsection{Site selection level}

Site selection is extremely important as the location of the installation can eliminate or reduce recognition factors. The process of selecting proper site starts by evaluating its suitability with respect to purpose of the installation. A particular site to be excellent from a CCD point of view, must achieves the needs of good CCD plan.

The following guidelines have to be followed to achieve a proper site:

a) Avoid distinctive layout Features: This could be achieved by avoiding constructing installation, whenever possible, near easily identifiable cultural or natural formations such as lakes, rivers, roads intersections, monuments or other conspicuous features, as they are easily identify the target even by photo interpreters or by the attackers. Designers must also be careful not to worsen the problem by adding new prominent features.

b) Select Complex Terrain Patterns: This could be achieved by placing the facility, when possible, in a region of a complex terrain pattern rather than a simple or relatively featureless terrain. 


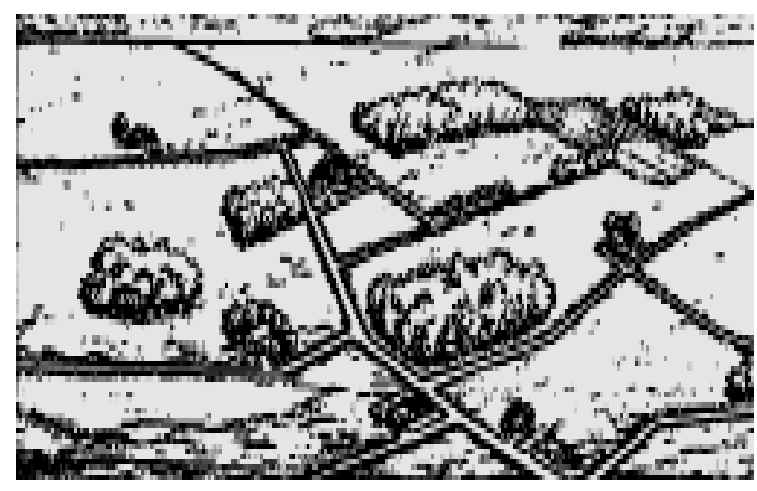

Simple terrain pattern

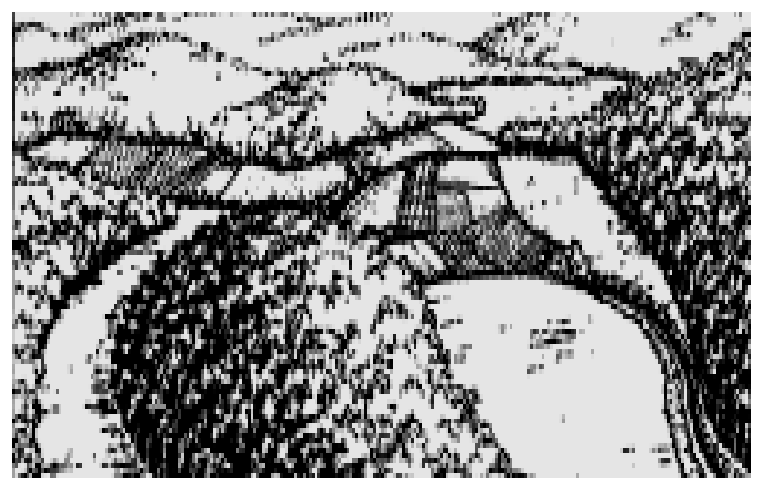

Complex terrain pattern

c) Select a concealed location: This could be achieved by studying the terrain topography features, trying to locate installations so that they are obscured or partially obscured by the complex terrain. For example, locating the facility under and around tall trees, rock formations or other natural compositions.

\subsection{Urban planning \&architecture design level}

Providing proper CCD plan to the urban planning and the architecture design process of new installations is more effective and can be achieved easier than trying to provide it for already existing ones.

The following guidelines will achieve proper CCD plan for the architecture design process:

a) Avoid regular patterns: This could be achieved by assembling installations located in natural topography in organic patterns especially in open areas such as desert or agricultural sectors. Also following the layout pattern of local planning is essential. Grid patterns should be avoided as they represent a key targeting cue to aerial reconnaissance and to attacking aircrafts.

b) Avoid the main factors affecting the building visual recognition (see 3): This could be achieved by following a disguise plan that imitate local architecture scale, style, colors, planting and other details that have to be carefully copied from the original layout. 

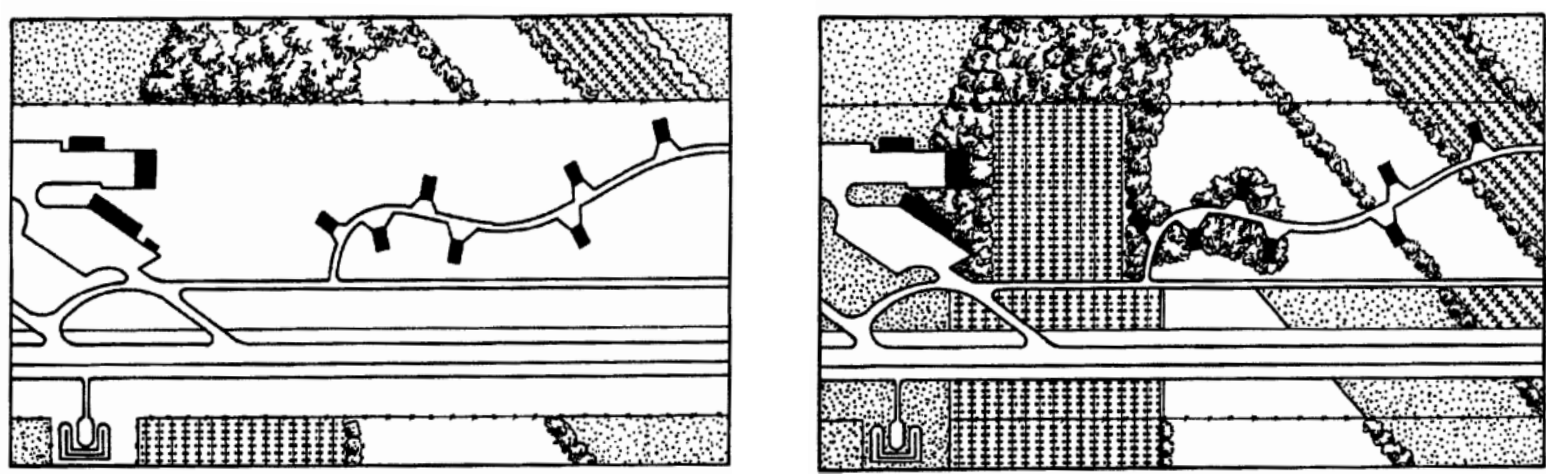

Before and after Camouflage by imitating the surrounding vegetation patterns
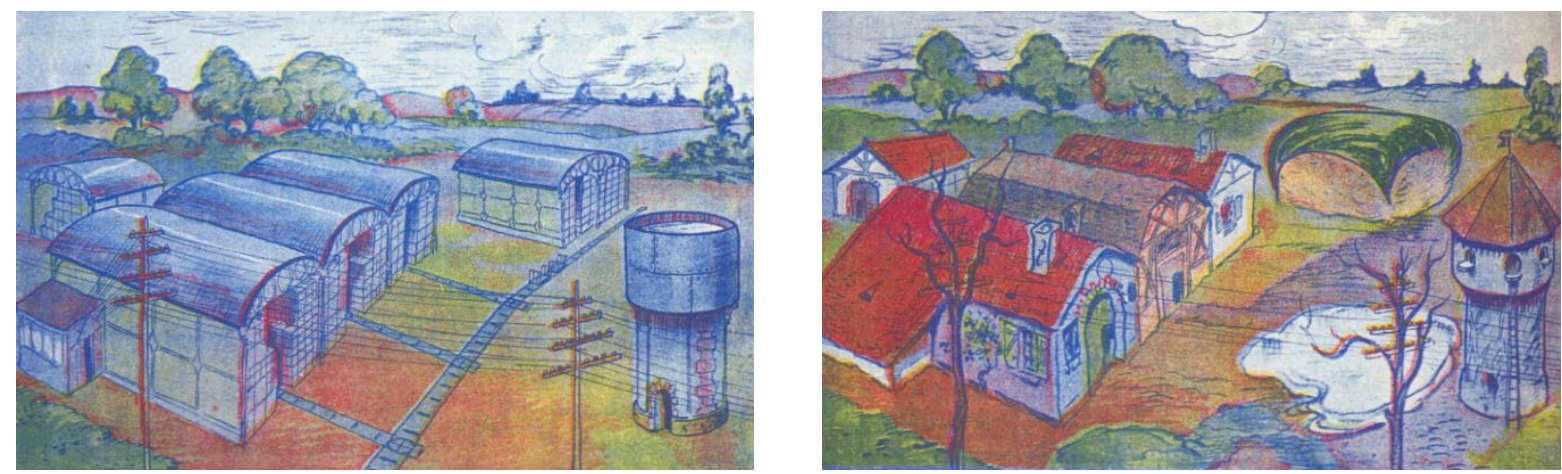

French munitions store before and after camouflage treatment by imitating the native dwelling architecture [16]

c) Use soil cover if possible: This could be achieved by partially burying the installations in topography to provide effective concealment treatments and prevent visual reconnaissance means. To reserve a normal sky line, the layout is supplemented with trees, bushes and green areas.

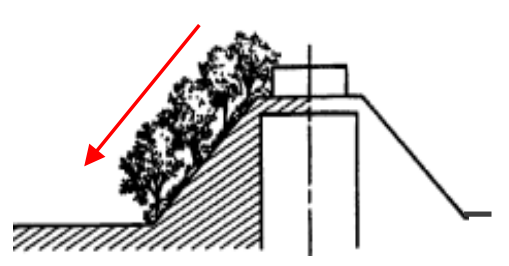

Not very effective

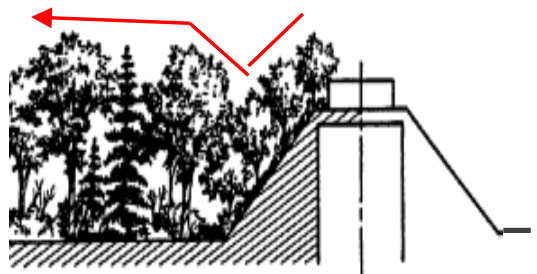

Moderately effective

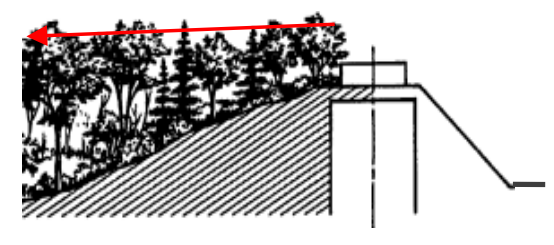

Very effective

camouflage by a soil embankment supplemented with trees and bushes

d) Take advantage of Dispersal: This could be achieved by dispersing installations that could be valuable targets so that they cannot be attacked at the same time.

e) Camouflage landscape communication features: Access roads and nearby parking areas for specific installation must have a special treatments to conceal 
and camouflage them, to not act as landmarks and reveal the installation location.
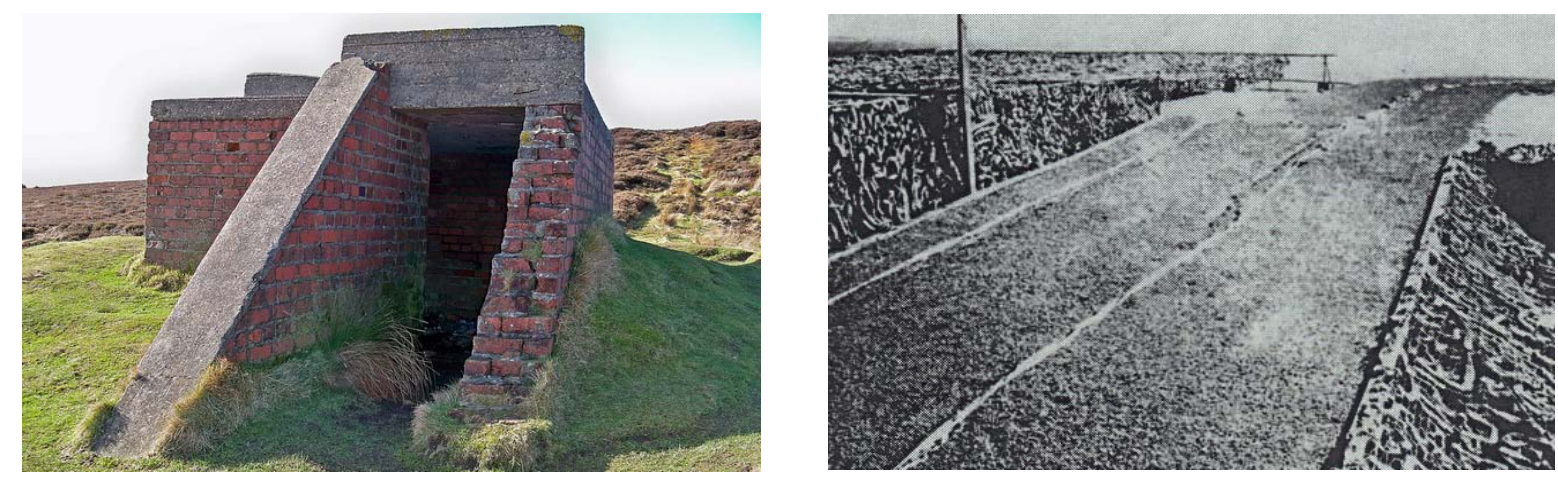

Left: Decoy for entries or exits of fortifications [20]

Right: False roads decrease the possibilities of locating important installation [10]

\section{6-3 Construction materials level}

Camouflage materials enhance anti-detection possibilities by reducing the target's reflectance level in the visible portion of the EM spectrum.

Using natural materials soil embankments and vegetations from the native surroundings blend installation with its environment.

From the other side man-made materials such as improved paints, camouflage nets, decoy material and smoke can greatly enhance CCD efforts.

\section{7- CONCLOUSIONS}

- Camouflage and concealment of vital installations became essential after the rapid development in visual reconnaissance means and accuracy of weapons.

- The most plentiful, reliable, and timely reconnaissance sensors are the visual. Therefore, CCD effective methods in the visual spectrum are extremely important to be applied.

- Camouflage and concealment design process depends on three levels, the site selection level, the urban planning \& architecture design level and the construction materials level. By integrating the three levels, maximum camouflage and concealment is achieved against reconnaissance and acquisition threats.

- The importance of camouflage and concealment methods to protect installations against reconnaissance and acquisition threats make an obligation on architects to contribute in saving these assets by : 
- The need of a non-traditional architecture design guidelines proportionate with the function and location of the installations taking into consideration the rapid development in the strategies of modern warfare and reconnaissance techniques.

- The need of using a complex planning processes to complicate the interpretation process of aerial photographs.

- The need to use portable, prefabricated installations and high-fidelity decoys in plausible locations increases the ability of maneuvers in the deception plans and reduces losses in souls and costs.

- The need of applying scientific and technological methodologies in designing and implementing camouflage and concealment plans either in developing the existing situations or in the construction of new projects.

\section{8-REFRENCES:}

[1] D. C. Schleher, Electronic warfare in the information age: Artech House, Inc., 1999.

[2] W. US Department of the Army, DC, CAMOUFLAGE,CONCEALMENT, AND DECOYS, 1999.

[3] T. M. Lillesand, et al., Remote sensing and image interpretation: John Wiley \& Sons Ltd, 2004.

[4] U. S. Army, FM 5-20 Camouflage.

[5] R. R. Behrens, "The theories of Abbott H. Thayer: father of camouflage," Leonardo, pp. 291-296, 1988.

[6] S. Gerwehr, Glenn, Russell W, The art of darkness: deception and urban operations, 2000.

[7] D. O. T. ARMY, CAMOUFLAGE MATERIALS FM 5-22, 1956.

[8] G. Crawley, "Strategic scenography: staging the landscape of war," 2012.

[9] t. f. e. Wikipedia, "Universal Camouflage Pattern," ed, 2012.

[10] U.S.Army, camouflage of fixed installation, 2006.

[11] t. f. e. Wikipedia, "Polygonal patterned ground," ed, 2011

[12] k. m. a. ottar, Architecture of Aggression, 1973.

[13] t. f. e. Wikipedia. Maginot Line [Online].

[14] J. M. pictures. (2009). www.pbase.com/image/116220007.

[15] m. floss-USA. http://mentalfloss.com/article/23877/camouflaging-airplanefactory.

[16] H. N. Blechman, Alex, DPM: disruptive pattern material: an encyclopedia of camouflage: nature, military, culture, 2011.

[17] U. h. photos, "Boeing Plant Seattle Washington," ed, 2009.

[18] c. u. U.S. Army, "AIR SMOKESCREENS ", ed, April 2011.

[19] t. f. e. Wikipedia, "Smoke screen," ed, 2012.

[20] http://www.flickr.com/photos/kev51/6331910795/sizes/l/in/photostream/. 
Proceedings of the $\mathbf{1 0}^{\text {th }}$ ICCAE-10 Conference, 27-29 May, 2014

AE-2 